\title{
CAN GEOINFORMATION HELP TO BETTER PROTECT INFORMAL SETTLEMENTS? - A CONCEPT FOR THE CITY OF MEDELLIN
}

\author{
W. Dorner ${ }^{1 *}$, L. Ramirez Camargo ${ }^{1}$, P. Hofmann ${ }^{1}$ \\ ${ }^{1}$ Institute for Applied Informatics, Technische Hochschule Deggendorf, \\ 94078 Freyung, Germany - (wolfgang.dorner, luis.ramirez-camargo, peter.hofmann)@th-deg.de
}

KEY WORDS: Early Warning systems, Landslides, VGI, Smartphone, UAS,

\begin{abstract}
:
New contributions to disaster research need to address the increasing vulnerability of informal settlements in a changing climate situation. Informal settlements are frequently built in hazardous areas and are often left out of traditional disaster risk management concepts. Hence, formal and informal societal structures, as well as technical systems to warn against, handle or mitigate natural hazards, need to evolve. Within the project Inform@Risk we are addressing these issues based on a case study in Medellín (Colombia). Here, as a result of civil conflicts informal dwellings were partly constructed by people displaced from rural areas. They are mainly located in the urban peripheral areas along steep and unstable slopes, where the resettlement of all inhabitants at risk of landslides is unfeasible. This contribution presents the technical infrastructure and the concept to incorporate geodata from different sources in an integrated landslide early warning system for some selected informal settlements of Medellin. Special attention is given to possibilities on how building societal institutions, supported by information systems, increases local resilience. Using geoformation as a basis, we will combine classical participatory planning methods with digitally assisted concepts. These include combining satellite and UAS based remote sensing data with terrestrial sensor networks, crowd sourcing and citizen science to collect volunteered geographic information about the settlement and its environmental parameters, as well as distribute this information and disseminate warnings to the local population.
\end{abstract}

\section{INTRODUCTION}

Besides other challenges, informal settlements are often located in hazardous areas prone to landslides, floods and wild fire. Policies and actions are often limited by the legal status of settlements and there is usually a lack of alternatives to protect population in non-formal settlements at risk. While classical urban development strategies try to consider natural hazards and avoid areas at risk or consider protection measures, informal settlements often tend to fill these areas at risk left aside by classical planning processes. Resettling the informal community is often not an option due to limited housing capacities and protection measures for the population become the only possible choice. Last but not least planning departments lack data to estimate the hazard potential, the objects at risk and the instruments to develop legally suitable tools, to increase the resilience of informal urban structures.

The risk of landslides in informal settlements in the Andes is unavoidable and measures should be taken to protect the life of the population living there. Geologically young mountains such as the Andes are prone to fatal events due to landslides (Petley, 2012). Such unstable soils are easily affected by the prevailing tropical weather and the risk of landslide is incremented by uncontrolled urbanization, the loss of native vegetation, deforestation, overgrazing, slope cuts and construction (failures) that negatively impact the hydrology of particular sites (Ojeda, 2006). Furthermore, single fatal landslides usually account for a relatively low number of deaths. In contrast, considering only events between 2004 and 2010, at least 2,620 non-seismic landslides took place, claiming more than 30,000 lives around the world (Petley, 2012). Recent estimations consider that worldwide yearly more than 4,300 persons die due to landslides (Froude \& Petley, 2018) and that the related costs of these catastrophes exceed $\$ 19$ billion per year (Haque et al., 2016).

Inform@Risk is a participatory planning and technology project that aims at developing an early warning system to increase resiliency against landslides in informal settlements. The project faces a set of questions that require an interdisciplinary approach: 1) How can we involve local stakeholders and especially local population in a participatory planning process to raise awareness for the risk of landslides and prepare warning and protection measures? 2) Can remote sensing, citizen science and ground measurements be combined to provide a basic spatial data set for planning and warning? While the first question defines the requirements on data collection, the latter question is especially interesting from a data perspective.

Spatial data is the key for disaster management processes, but especially informal settlements lack a planning basis as well as consistent and up to date data. This article provides an insight in the Inform@Risk Project approach to collect, derive and generate the necessary data base for the thorough warning system development on hand of an informal settlement. The presented approach is based on first results of a case study settlement in Medellín, Colombia. The Aburrá valley, surrounded by a belt of unstable volcanic soils, where Medellín and its suburbs are located, has been the location of recurrent fatal landslide that have taken hundreds of lives in the last years. Under the current estimations of climate change and

Corresponding author 
urbanization, these numbers are expected to increase (Gariano \& Guzzetti, 2016).

This document is structured as follows: First an overview of similar approaches to Inform@Risk and underlying scientific work are presented in section 2 . Then we will introduce the case study area in Medellin's mountainous periphery in section 3 and present the scientific and technical concept of the project in section 4. Finally, section 5 draws conclusions

\section{RELATED WORK}

Following the definition of the United Nations, the objective of people-centred early warning systems is to reduce the possibility of loss of life and livelihoods, personal injury, damage to property and the environment. This should be achieved by empowering communities and individuals threatened by hazards to act in sufficient time an appropriate manner (United Nations, 2006). This objective has been adopted and ratified in both the Hyogo (United Nations, 2005) and Sendai (United Nations, 2015) Frameworks for disaster risk reduction, which cover the period 2005 - 2030. The recommendations and actions proposed in these frameworks range from the global to the local scale. They have laid the foundation for the further development of global initiatives such as the global risk data platform (United Nations Environmental Programme \& United Nations Office for Disaster Risk Reduction, 2013) and have motivated a long list of early warning systems around the world. However, in contrast to the high number of locations at risk of landslides and the potentially high number of local early warning systems that have been set-up or are in development around the world, a thorough review of such systems reported in scientific literature shows that only 29 cases are properly documented (Pecoraro, Calvello, \& Piciullo, 2019). It is worth noting that most of these reported early warning systems are located in Europe. While Asia, a continent with high landslide risk possesses only few examples of early warning systems, others in the same situation such as Latin America and Africa do not report any single case (Pecoraro et al., 2019). This situation correlates also with studies linking landslides risk with climate, there is a long list of countries that will be affected by such events, where non a single study has been made (Gariano \& Guzzetti, 2016)

The UN/ISDR Platform for the Promotion of Early Warning (2016) characterizes the core elements of a complete and effective people-centred early warning system in the following way:

a. Risk knowledge: systematically collect data and undertake risk assessments

b. Monitoring and warning service: develop hazard monitoring and early warning services

c. Dissemination and communication: communicate risk information and early warnings

d. Response capability: build national and community response capabilities

Such elements are stablished in the early warning systems literature and are also the elements that we adopt to select the related work presented here. One of the most studied early warning systems is the one of Ancona City in Italy. It is managed by the Ancona Monitoring Center and information about it can be found in Cotecchia (2006), Cardellini and Osimani (2008), Cardinaletti et al. (2011) and Baroň et al. (2013). The Ancona early warning system includes a monitoring system with a total station, GPS, rain gauge, a differential monitoring of instability column and perforated standpipes. The alert parameters are displacement, rainfall and groundwater level, which lead to alerts in case empirical thresholds are surpassed. The risk information distribution tools of this early warning system include internal SMS, and direct calls. The decision about making or cancelling an alert is in the hands of the civil protection department of the municipality. Similar information and monitoring systems can be found in the Alice Bel Colle municipality in Italy (Olivieri, Lovisolo, \& Crosta, 2012). In this case both SMS and direct calls are made to the staff on duty at the monitoring centre and the decision about issuing a warning is made by the technical staff at the Alice Bel Colle Municipality. Here, pre-defined empirical displacement thresholds are the alert criterion and measurements are made with perforated standpipes, inclinometers and a differential monitoring of the instability column. Further cases in Europe such as La Valette in France managed by the "Service de Restauration des Terrains en Montagne" also use photogrammetric and remote sensing instruments such as cameras and LiDAR to monitor the slope. One well documented case in Asia is the early warning system of Wushan Town in the Three Gorges Reservoir area in China managed by the ministry of Land and Resources (Wang et al., 2008; Y. Yin, Wang, Gao, \& Li, 2010). For this early warning system, warning statements are made public through a website and the government is responsible for issuing the alerts. Additional to the measurement instruments used in the previously presented examples, time domain reflectometers, piezometers, optic fibre and water level meters are also put in place. However, in this particular Asian example there is no use of LiDAR or cameras. The latter is e.g. one of the main instruments in use in the Taiwan torrents (H.-Y. Yin, 2011). One case of an early warning system managed by a research institution is located in Wollogong, Australia (C. Flentje, 2006). The University of Wollogong has installed inclinometers, piezometers and rain gauge at multiple sites of the city for monitoring purposes. The landslide research team warns the public through a web page in case the rainfall surpasses an intensity-duration indicator, which has been set depending on correlations applied to historical data. One of the main developments in this case is a web Geographic Information System based landslide inventory of the whole city and surrounding areas that serves to preserve the historical data and to inform the public(P. Flentje \& Chowdhury, 2005).

Most of the cases considered by Pecoraro et al., 2019 present redundant systems in terms of measurement by using combinations of geotechnical, geodetic (ground and satellite based), remote sensing and photogrammetric techniques and make use of multiple communication technologies for warnings. However, none of the examples report on mechanisms to account for observations or participation of the population at risk itself in the monitoring or warning processes and systems. Classical participatory processes take time and tend to be used for risk mitigation through infrastructural measures and landscapes interventions (see e.g. Drosou (2019) and Clanghorn \& Werthmann (2015)) and not for monitoring.

\section{CASE STUDY AREA: INFORMAL SETTLEMENTS OF MEDELLÍN, COLOMBIA}

Medellin is the second largest city of Colombia with around 2.5 million inhabitants and a metropolitan area that reaches a population of 3,9 million people. The city is located in the Aburrá valley, which topography represents an enormous constrain for the further expansion of the city. The valley has an 
extent of approximately $20 \mathrm{~km}$ and the average width of $5 \mathrm{~km}$. It's lowest part is located at 1,500 meters above sea level and the surrounding mountains reach altitudes around 3,000 meters above the see level. The consequence of this narrow structure and the drastic altitude difference between the bottom of the valley and its surrounding mountains are slopes, at both, west and east sides of the valley, which easily reach inclinations above $40 \%$ and $60 \%$. The east side, which is the riskiest for human settlements due to its soil composition mainly based on fractured and structurally weak dunitic rock, is at the same time the most attractive for the population. This occurs due to its proximity to the city centre, roads, public utilities and to existing non-formal settlements (Claghorn \& Werthmann, 2015). Figures 1 and 2 were recently made at the east side of the valley and should give the reader an idea about the settlements that have been built in this area. The first photograph was taken from the top of one slope and with direction of the city centre while the second one was taken from one slope aiming at the neighbour slope and its vertical profile.

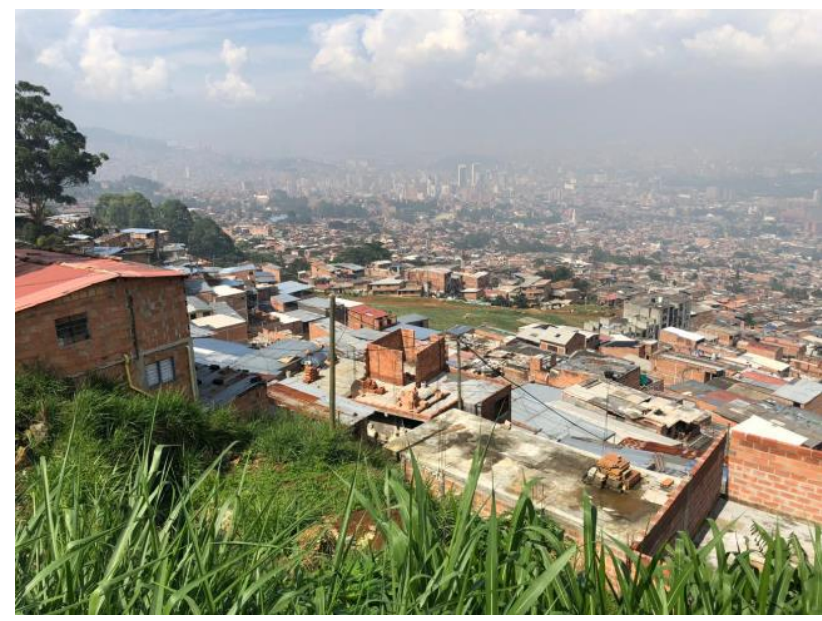

Figure 1. Photograph of the east side of the Aburrá valley, from the top of a mountain pointing at Medellín's city centre (This Photo was made by the Team of the Technical University Munich in April 2019).

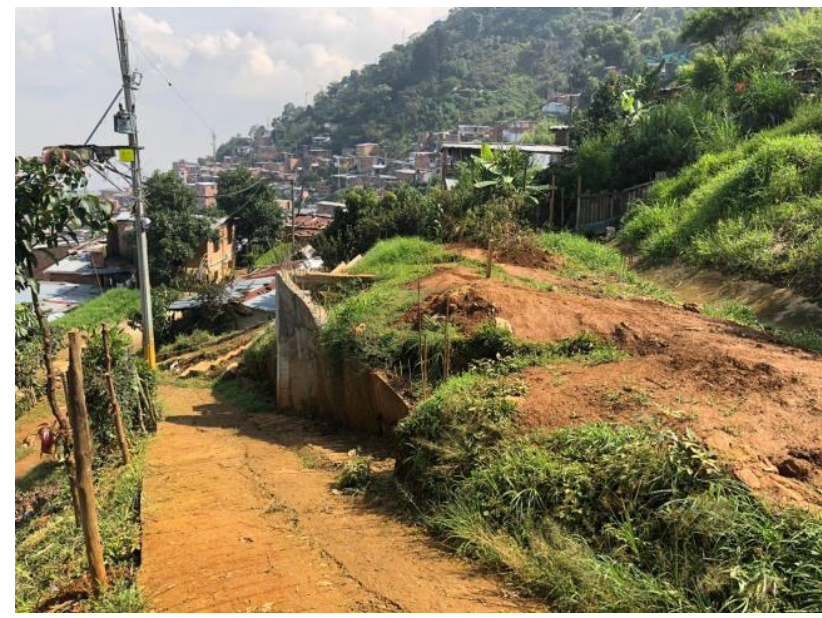

Figure 2. Photograph of the east side of the Aburrá valley. It shows the vertical profile of one slope from another slope (This Photo was made by the Team of the Technical University Munich in April 2019).
The start of the history of risk management in Colombia dates back to 1989 with the establishment of the National System for the prevention and attention of disasters at the national level. At the municipal level the Agreement 14 of 1994 founded the Municipal System for the Prevention and Attention of disasters. These systems that were mainly dedicated to the attention and prevention of disasters and emergencies evolved to locally adapted risk management systems that aim at sustainable development and to adapt to climate change. The basis of the current Risk management systems is the Law 1523 of 2012 that creates the National Unit for Disasters Risk Management at the national level. It's counterpart at the municipal level is the Administrative Department of Disaster Risk Management DAGRD. The latter is responsible for the development and implementation of municipal risk management plans, a municipal response strategy and recovery plans. In the case of Medellín these are articulated in the City's Land Use and Development Plans as well as in the Aburra river and Local Emergency and Risk management plans. One of the results of the risk management strategy of the city is a Multi-Hazard Map where it can be seen that a considerable part of the slopes of the mountains around the bottom part of the Aburrá valley have significant risk of landslides (Alcaldía de Medellín, 2015).

In spite of the recognized hazard, the multiple examples of fatal landslides recorded in the area at least since 1987 (Ojeda, 2006) and the efforts of the authorities to create and implement stateof-the-art Risk management plans, people continue to settle in hazardous areas. Unfortunately, there are no signals that this situation might change and for hundreds of thousands of people there is no economically viable alternative to re-settle. Furthermore, this problematic is common to most of the major cities in across the Andes.

Inform@ risk precisely addresses informal settlements at risk of landslides at the slopes of the mountains surrounding Medellín. The objective is to create a low cost monitoring, warning and communication system to increase the resiliency of the community. This system should be economic and flexible enough to be replicated in locations with similar conditions along the Andes. In order to develop the early warning system a case study area will intensively studied and monitored with a multi sensor network that is explained in the next section of this paper. The selection of the study area is currently in progress but a list of 4 pre-selected areas (each with a few hundred inhabitants) based on the level of risk and accessibility is already defined. For the aim of the project it was necessary to narrow down a case study area that fulfils the following criteria: 1) it is representative for other settlements 2) it is exposed to the risk of landslides, but the resilience can be improved without enormous technical measures and at high costs. Main criterion for the further selection of the study site will be the readiness of the population to work jointly with the research team.

\section{AN INTEGRATED LANDSLIDE EARLY WARNING SYSTEM FOR INFORMAL SETTLEMENTS}

Inform@risk follows the guidelines of the Sendai framework for disaster risk reduction and is especially motivated by the guiding principal "m". This states that: "Developing countries, in particular the least developed countries, small island developing States, landlocked developing countries and African countries, as well as middle-income and other countries facing specific disaster risk challenges, need adequate, sustainable and timely provision of support, including through finance, technology transfer and capacity building from developed 
countries and partners tailored to their needs and priorities, as identified by them."

We bring state of the art technology and know-how to the study area with the hope that we can tailor it to the local requirements and can actually contribute to improve the resiliency of the community. Moreover, in order to end the systematic lack of scientific documentation about local early warning systems for landslides in Latin America, encountered by Pecoraro et al (2019), this should be the first of a series of papers describing the planning, commissioning and the results from the first years of operation of the Inform@ @isk early warning system for an informal settlement in the Aburrá valley, Colombia.

For any form of risk assessment or the planning of protection measures the underlying data is missing in informal settlements. Due to their character classical settlement statistics as well as planning data, documentation of infrastructure or the exposure to natural hazards are missing. This prohibits any kind of overall risk assessment on a city scale as well as detailed planning for individual buildings or quarters. This lack of data in combination with the legal status of informal settlements forbids classical planning concepts and protection measures. At this background, alternative methods to gather relevant data and information are necessary. It is important to note, that data availability for the formal part of Medellín is actually high and that Inform@Risk is certainly not the first project gathering data of the informal settlements of the Aburrá valley. As described in previous sections, the City of Medellín has even a multi-hazard map for the whole Valley and slopes and informal neighbourhoods at risk are identified. It is only when conducting a detailed risk assessment at the slope level in informal areas that high resolution data is missing. Furthermore, there are previous studies that address particular slopes in informal areas in the Aburrá Valley and one of them dedicated to risk mitigation through community-based landscape interventions (Claghorn \& Werthmann, 2015) is one of the main motivations for Inform@Risk.

Following this background, in Inform@Risk we investigate the potential of remote sensing data of any kind in conjunction with diverse image analysis methods at different scale levels. E.g. satellite and airborne imagery is used at city or district level, while UAS-based images are used at neighbourhood level. While satellite data can be used to delineate and differentiate informal settlements by their typical spatial patterns, UASbased and airborne data can be used to identify single houses. With UAS-based data it is even possible to perform very detailed 3D reconstructions of informal settlements. With this data key information for vulnerability assessments such as number of dwellers per building or quality of building structure can be estimated. A further valuable data source is data derived from or via mobile devices and volunteered geography (Hachmann, Arsanjani, \& Vaz, 2018; Siriba \& Dalyot, 2017; W. Song \& G. Sun, 2010). E.g. by analysing time and position of mobile devices (smartphones) hotspost of an area can be identified which indicate locations with (temporary) increased risk of life losses. Vice versa dwellers with smartphones can also actively incorporate and contribute to the early warning system by mapping critical points or areas and taking photographs of them. This captured data will then be uploaded into a dedicated cloud and analysed.

Drones or unmanned Air-Vehicles (UAVs) are meanwhile used for a variety of data capturing activities, especially for large scale data. In comparison to satellite data or airborne data, they can be captured immediately and the data acquisition method is relatively flexible (UAS can be piloted from ground and usually no pilot license is necessary). Further, UAS can fly at very low altitude, which enables them to deliver very detailed data. Thus, they play an increasing role for data acquisition of informal settlements (C. M. Gevaert, Persello, Sliuzas, \& Vosselman, 2017; C. Gevaert, Persello, \& Vosselman, 2016; Mboga, Persello, Bergado, \& Stein, 2017) as well as for monitoring landslides (Niethammer, James, Rothmund, Travelletti, \& Joswig, 2012; Niethammer, Rothmund, James, Travelletti, \& Joswig, 2010; Turner, Lucieer, \& De Jong, 2015). In the context of Inform@Risk the usage of UAS is similar the way as is reported by Casagli et al. (2017). That is, capturing the (informal) settlement structures very detailed by photogrammetric $3 \mathrm{D}$ reconstruction and to monitor slopes in conjunction with a fixed mounted geo-sensor network. The latter detects sub-surface movements and humidity while with the UAS based data a very detailed DEM can be generated. In conjunction with this high resolution DEM slow mass movements can be tracked if several follow-up flight campaigns are applied. Depending on the mass movements' velocity thresholds need to be determined in order to decide for alarming. Additionally we intend to validate data derived from space- or airborne instruments with UAS-based data and investigate the degree of mutual complementarity of these data types for this very application context. The captured UASbased data will also act as data source for local decision support and 3D visualization of the settlement situation, e.g. in handheld devices. UAS based 3D reconstructions have additionally the potential to be used for an ad hoc determination of the fastest way out in case of an alert. They could also be used to visualize this route in satnav-like manner or even via augmented reality.

Baroň \& Supper (2013) already reported on the high potential of remote sensing technologies for warning purposes but criticises their maturity for geotechnical applications. In Inform@Risk we expect to further develop these technologies for geotechnical applications but also strongly rely on the use of proven sub-surface monitoring technologies. A cost-effective monitoring system for subsurface deformations using the time domain reflectometry method as described by Thuro et al. (2010) will be set in place. Furthermore, the data obtained with this system will be the input for a $2 \mathrm{D}$ continuum numerical model that will serve to analyse the slope stability with respect to pore water pressure and precipitation rates (Aversa, Cascini, Picarelli, \& Scavia, 2016). It is important to note that the installation of the measurement systems will follow a participative approach, where the location of the sensors is known to community. These sites will not have restricted access and on the contrary, these will be used to disseminate information about the sensors, the early warning system and the project. Elements will be designed to provide visibility and multifunctional use, increasing perception and improving daily living conditions for informal dwellers (see figure 3).

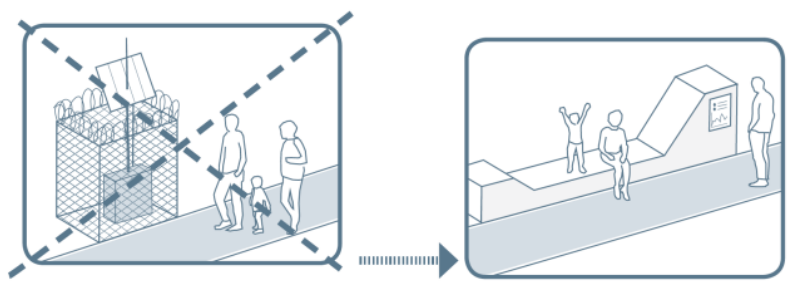

Figure 3: Spatial Integration of Early Warning and Sensing System (Werthman, C.) 
To deal with the lack of data in a quickly developing environment it is necessary first to acquire initial data and second to update the data to follow the development of the settlement pattern as well as changes in the landscape that might influence the probability of hazards and risk to persons and assets. Therefore the remote sensing and the subsurface data will be not only complemented with initial surveys to the community but also a smartphone based app will be developed. This will make use of smartphone sensors and users' contributions such as comments and photos to gather data in high spatial and temporal resolution. As experienced in projects such as PubInPlan (Küspert \& Zink, 2017), a project on digital based public participation in planning processes, inhabitants as local experts can provide valuable detailed insights not available to external planners as domain experts. The approach is facing two problems: 1) Are people willing to adapt the solution and contribute? 2) Will there be sufficient photos for $3 \mathrm{D}$ analysis and change detection? Main risk to this approach is the willingness as well as continuous awareness of inhabitants to first use the app and second really to contribute through data. To provide an additional incentive to inhabitants also a warning functionality for landslides should be included in the app. Which app specific strategies to catch the users interest could be used in the context of urban planning and might be transferred from commercial apps, is still issue of discussion and will have to be tested.

Summarizing, in order to construct a complete and effective people-centred early warning system for an informal settlement of the Aburrá valley, Inform@Risk will rely in a combination of technical and human sensor and communication systems. The data collection for the initial risk assessment will be gathered using remote sensing technologies, ground measurements and local knowledge. The monitoring and warning service will be built on a combination of remote sensing technologies, a proven sub-surface measurement system and voluntary geography strategies supported on a smartphone based application. This latter is together with monthly stakeholder workshops the core for dissemination. Furthermore, the smartphone based application itself is a state-of-the-art technology to communicate risk, which should also serve to construct links within the community that help to improve the community's response capabilities.

\section{CONCLUSIONS}

Early warning systems might be the last resort to protect lives in informal settlements at high risk of natural catastrophes, where relocation is unfeasible and infrastructural measures cannot be taken due to legal or economic reasons. Such systems are operating for early warning of landslides in multiple locations in the world but there is scarce documentation of them in large areas at high risk such as the Andes mountain system. The project Inform@ risk should be the first to finish this trend by providing documentation on a people-centred early warning system for an informal settlement of Medellin, Colombia. Beyond a mere scientific work and dissemination, the project aims mainly at improving the resiliency of the community living in this settlements. To achieve this the Project team, in collaboration with multiple local organizations, will put stateof-the-art technology and know-how at service of the community. One of the key elements of the system is a multisensor network, where geodata coming from remote sensing technologies, crowd sourcing and citizen science approaches, should fill data gaps to improve risk assessment and monitoring of landslides in such settlements. Moreover, a Smartphone application that serves for data gathering and dissemination should close the loop and help to communicate risk and to increase the community's response capabilities. Geoinformation alone cannot solve the problem but in the framework of Inform@Risk we expect to demonstrate how it can contribute to better protect informal settlements from landslides.

\section{ACKNOWLEDGEMENTS}

The project Inform@Risk - "Stärkung der Resilienz informeller Siedlungen gegen Hangbewegungen" is funded by the German Federal Ministry of Education and Research as part of the FONA Client II initiative and supported, among others, by the Colombian Government. The consortium is led by the Institute of Landscape Architecture of the University Hannover- ILA, its further members in Germany are from the Technische Hochschule Deggendorf - THD, the Deutsche Zentrum für Luftund Raumfahrt/German Center for Aerospace Research - DLR, , Technical University Munich - Chair for Engineering Geology - TUM, AlpGeorisk and SLU, In Colombia, URBAM University of EAFIT, Geological Society of Colombia, Municipal Department of Risk Management in Medellin DAGRD, Municipal Planning Department, the NGO Convivamos and the Resilience Office of Medellin.

\section{REFERENCES}

Alcaldía de Medellín. (2015). Plan Municipal de Gestión del Riesgo de Desastres del Municipio de Medellín (PMGRD).

Aversa, S., Cascini, L., Picarelli, L., \& Scavia, C. (Eds.). (2016). Landslides and Engineered Slopes. Experience, Theory and Practice: Proceedings of the 12th International Symposium on Landslides (Napoli, Italy, 12-19 June 2016). https://doi.org/10.1201/b21520

Baroň, I., \& Supper, R. (2013). Application and reliability of techniques for landslide site investigation, monitoring and early warning \&ndash; outcomes from a questionnaire study. Natural Hazards and Earth System Sciences, 13(12), 3157-3168. https://doi.org/10.5194/nhess-13-3157-2013

Cardellini, S., \& Osimani, P. (2008). Living with Landslides: the Ancona Case History and Early Warning System. 6.

Cardinaletti, M., Cardellini, S., \& NInivaggi, A. (2011). The integrate landslide managing system of Ancona. Retrieved

from https://www.preventionweb.net/applications/hfa/lgsat/ en/image/href/512

Casagli, N., Frodella, W., Morelli, S., Tofani, V., Ciampalini, A., Intrieri, E., ... Lu, P. (2017). Spaceborne, UAV and ground-based remote sensing techniques for landslide mapping, monitoring and early warning. Geoenvironmental Disasters, 4(1), 9. https://doi.org/10.1186/s40677-017-0073-1

Claghorn, J., \& Werthmann, C. (2015). Shifting ground: Landslide risk mitigation through community-based landscape interventions. Journal of Landscape Architecture, 10(1), 6-15. https://doi.org/10.1080/18626033.2015.1011419

Cotecchia, V. (2006). The Second Hans Cloos Lecture. Experience drawn from the great Ancona landslide of 1982. Bulletin of Engineering Geology and the 
Environment, $\quad 65(1)$ https://doi.org/10.1007/s10064-005-0024-z

Drosou, N., Soetanto, R., Hermawan, F., Chmutina, K., Bosher, L., \& Hatmoko, J. U. D. (2019). Key Factors Influencing Wider Adoption of Blue-Green Infrastructure in Developing Cities. Water, 11(6), 1234. https://doi.org/10.3390/w11061234

Flentje, C. (2006). Observational approach for urban landslide management. (522), 13.

Flentje, P., \& Chowdhury, R. N. (2005). Managing landslide hazards on the Illawarra escarpment. 15.

Froude, M. J., \& Petley, D. N. (2018). Global fatal landslide occurrence from 2004 to 2016. Natural Hazards and Earth System Sciences, 18(8), 2161-2181. https://doi.org/10.5194/nhess-18-2161-2018

Gariano, S. L., \& Guzzetti, F. (2016). Landslides in a changing climate. Earth-Science Reviews, 162, 227-252. https://doi.org/10.1016/j.earscirev.2016.08.011

Gevaert, C. M., Persello, C., Sliuzas, R., \& Vosselman, G. (2017). Informal settlement classification using pointcloud and image-based features from UAV data. ISPRS Journal of Photogrammetry and Remote Sensing, 125, 225-236. https://doi.org/10.1016/j.isprsjprs.2017.01.017

Gevaert, C., Persello, C., \& Vosselman, G. (2016). Optimizing Multiple Kernel Learning for the Classification of UAV Data. Remote Sensing, 8(12), 1025 https://doi.org/10.3390/rs8121025

Hachmann, S., Arsanjani, J. J., \& Vaz, E. (2018). Spatial data for slum upgrading: Volunteered Geographic Information and the role of citizen science. Habitat International, 72, 18-26.

Haque, U., Blum, P., Silva, P. F. da, Andersen, P., Pilz, J., Chalov, S. R., ... Keellings, D. (2016). Fatal landslides in Europe. Landslides, 13(6), 1545-1554. https://doi.org/10.1007/s10346-016-0689-3

Küspert, S., \& Zink, R. (2017). Concept of a Digital Communication Platform to Increase the Citizens' Interest in Spatial Planning. Retrieved from http://gispoint.de/fileadmin/user_upload/paper_gis_op en/DLA_2017/537629014.pdf

Mboga, N., Persello, C., Bergado, J., \& Stein, A. (2017). Detection of Informal Settlements from VHR Images Using Convolutional Neural Networks. Remote Sensing, 9(11), 1106 https://doi.org/10.3390/rs9111106

Niethammer, U., James, M. R., Rothmund, S., Travelletti, J., \& Joswig, M. (2012). UAV-based remote sensing of the Super-Sauze landslide: Evaluation and results. Engineering Geology, 128, 2-11. https://doi.org/10.1016/j.enggeo.2011.03.012

Niethammer, U., Rothmund, S., James, M. R., Travelletti, J., \& Joswig, M. (2010). UAV-BASED REMOTE SENSING OF LANDSLIDES. 7.

Ojeda, D. (2006). Landslides in Colombia and their impact on towns and cities. (112), 13.

Olivieri, W., Lovisolo, M., \& Crosta, G. B. (2012). Continuous geotechnical monitoring for alert thresholds and hazard management. Landslides and Engineered Slopes, 1929-1934.

Pecoraro, G., Calvello, M., \& Piciullo, L. (2019). Monitoring strategies for local landslide early warning systems. Landslides, 16(2), 213-231. https://doi.org/10.1007/s10346-018-1068-z
Petley, D. (2012). Global patterns of loss of life from landslides. Geology, 40(10), 927-930. https://doi.org/10.1130/G33217.1

Siriba, D. N., \& Dalyot, S. (2017). Adoption of volunteered geographic information into the formal land administration system in Kenya. Land Use Policy, 63, 279-287.

Thuro, K., Singer, J., Festl, J., Wunderlich, T., Wasmeier, P., Reith, C., ... Schuhbäck, S. (2010). New landslide monitoring techniques - developments and experiences of the alpEWAS project. Journal of Applied Geodesy, 4(2). https://doi.org/10.1515/jag.2010.008

Turner, D., Lucieer, A., \& De Jong, S. M. (2015). Time Series Analysis of Landslide Dynamics Using an Unmanned Aerial Vehicle (UAV). Remote Sensing, 7(2), 17361757. https://doi.org/10.3390/rs70201736

UN/ISDR Platform for the Promotion of Early Warning. (2016). Developing Early Warning Systems: A Check List. Retrieved

from https://www.unisdr.org/2006/ppew/inforesources/ewc3/checklist/English.pdf

United Nations. (2005). Hyogo Framework for Action 2005 2015.

United Nations. (2006). Global Survey of Early Warning Systems. Retrieved from https://www.unisdr.org/2006/ppew/inforesources/ewc3/Global-Survey-of-Early-WarningSystems.pdf

United Nations. (2015). Sendai Framework for Disaster Risk Reduction 2015 - 2030.

United Nations Environmental Programme, \& United Nations Office for Disaster Risk Reduction. (2013). Global Risk Data Platform. Retrieved 23 July 2019, from https://preview.grid.unep.ch/index.php?preview=abou t\&lang=eng

W. Song, \& G. Sun. (2010). The role of mobile volunteered geographic information in urban management. 2010 18th International Conference on Geoinformatics, 15.

https://doi.org/10.1109/GEOINFORMATICS.2010.55 67728

Wang, F., Zhang, Y., Huo, Z., Peng, X., Araiba, K., \& Wang, G. (2008). Movement of the Shuping landslide in the first four years after the initial impoundment of the Three Gorges Dam Reservoir, China. Landslides, 5(3), 321-329. https://doi.org/10.1007/s10346-008$0128-1$

Yin, H.-Y. (2011). The present development of debris flow monitoring technology in Taiwan - A Case study presentation. Italian Journal of Engineering Geology and Environment, (201103), 623-631. https://doi.org/10.4408/IJEGE.2011-03.B-068

Yin, Y., Wang, H., Gao, Y., \& Li, X. (2010). Real-time monitoring and early warning of landslides at relocated Wushan Town, the Three Gorges Reservoir, China. Landslides, 7(3), 339-349. https://doi.org/10.1007/s10346-010-0220-1 